\title{
Global Research Talents: Analysis of Their Behavior and Publication/Citation Patterns ${ }^{1}$
}

\author{
Daně̌ BRZICA*
}

\begin{abstract}
We examine publication/citation $(P / C)$ patterns of 88,653 global most productive researchers (MPRs). We analyze the link between publication and citation activity and provide evidence regarding the extent to which top researchers scientific results are better than scientific results of others. Our second aim is to analyze the kinds of patterns that are occurring in P/C activities of top researchers. Major findings are that both quality and quantity parameters represent important feature of MPRs. The best among top researchers have substantially better parameters than those at the bottom level of ranking. We also find that many MPRs publish excellent publications and receive high number of citations. The best-cited publications have researchers exhibiting low number of total publications. Among factors contributing to success of MPRs are team, cooperation, specialization, Ph.D. supervising, international project participation, multipleuse products and some other factors. Finally, looking at the patterns characterizing 22 research fields reveals differences. The clinical medicine field, e.g., is the area of research with the largest number of published WoS documents and citations. Multidisciplinary sciences show significantly lower values. The only similarity is an average number of citations per paper.
\end{abstract}

Keywords: publications, citations, top researchers, hyper-prolific authors

JEL Classification: I20, I23, I29, O30, O34, O39

DOI: https://doi.org/10.31577/ekoncas.2021.08.05

\section{Introduction}

In times of growing global competition among countries in science, pressure on excellent results in publication of scientific results is intensifying. The existing environment provides numerous opportunities and incentives how to obtain

\footnotetext{
* Daneš BRZICA, Institute of Economic Research, Slovak Academy of Sciences, Šancová 56, 81105 Bratislava, Slovak Republic; e-mail: danes.brzica@savba.sk

${ }^{1}$ The support of the grant scheme VEGA No. 2/0138/18 is acknowledged.
} 
very good results in science. Simultaneously, competition contributes to increasing barriers for scientists to become top class researchers. Globally excellent results have become reserved for people with outstanding talent, excellent equipment tools, concepts, methods and the most attractive research topics. Despite increasing number of sources allocated to research and growing number of most productive researchers (MPRs), not all researchers and research teams are similarly successful in research result competition. Various factors lie behind real success or failure of published publications. In contrast to the evaluation of universities and research centers, the evaluation of individuals is less studied, as is also the issue of quantitatively extreme cases. Given the relatively small group of studies, devoted to analyzing the success of MPRs in publishing research papers and citations, and their different focus (see the literature review section), we believe that our approach will add another dimension and new results to the mosaic of studies of why some researchers are much more productive than others. Our research finds that MPRs have quite different results and the best ones in each category represent only minor part of the full sample.

The existing institutional set-up promotes only marginally the publication/ citation $(\mathrm{P} / \mathrm{C})$ activities of researchers in some countries while different situation exists in others. Both high presences of researchers in top publication and citation rankings provide, e.g., a visible sign to policymakers that their country is successful in science. Many countries have promoted policies to facilitate better results and cooperation between home and foreign scientists (particularly in life sciences). The implicit assumption underlying current effort to focus on production of top publication is that excellent publications fosters innovation and moves a country towards higher competitiveness levels. Empirical work concerning the importance of excellent scientific publications, however, relies almost exclusively on case studies focusing on specific, usually the most developed, countries. Currently more and more countries are considering policies that would promote top research, which should result in top class publications and more citations. This process is ongoing at the time when $\mathrm{P} / \mathrm{C}$ competition is increasing.

Despite improving conditions in publication opportunities, individual qualities of a researcher still continues to play a key role in the production of scientific knowledge. We know, in general, less about relations between various kinds of $\mathrm{P} / \mathrm{C}$ parameters in different layers of top researchers. This paper tries to fill partially this gap in research. We do so by focusing on two specific forms of scientific activities, namely publications and citations (cites - used here interchangeably). Our aim is to analyze the link between publication and citation activity and to provide evidence regarding the extent to which MPRs' scientific results are better than that of others. We analyze the kinds of patterns that are 
occurring in $\mathrm{P} / \mathrm{C}$ activities of top researchers and expect that their excellent outputs are likely to be result of characteristics of researchers (their expertise) and the area and focus of research itself rather than of broader conditions affecting their work. The data used in this paper comes from the bibliographic database Web of Science (WoS) and its Essential Science Indicators (ESI) product, which provides data about the publications and citations in various research fields. One of the most important categories is the highly cited papers (HCPs) category that shows the Top $1 \%$ of papers cited in the 22 research fields. Citations are important in science as they serve as an indicator of publication significance, utility, attention, visibility or short-term impact (see Szomszor et al., 2020). We study the P/C activity of top 88,653 researchers (full sample, FS), including those at the top of the ranking pyramid. We do not analyze development over time but focus on a single moment (snap shot). However, this snap shot represents cumulative data for the 10 years plus 4 months period (January 1, 2008 - April 30, 2018). Maximal values per researcher are for individual indicators as follow: WoS documents $=52278 ;$ CIT $=663490 ;$ CIT $/ \mathrm{P}=10586 ;$ TOPP $=798$. Our second aim is to analyze the kinds of patterns that are occurring in P/C activities of MPRs.

The paper is organized as follows. In the Section 1, we describe current situation regarding research in the area of $\mathrm{P} / \mathrm{C}$ activity. The Section 2 provides research issues and methodology. We formulate here basic elements of the research framework for our paper. In the Section 3, we introduce detailed characteristics of the database, the related indicators and discuss the evidence on $\mathrm{P} / \mathrm{C}$ patterns for the global scientific community. In the Section 4 distribution of P/C activity of MPRs is outlined. In the Section 5, we present the analysis of the data and present results. The Section 6 provides an overview of some factors contributing to excellent publication/citation performance. The concluding section summarizes the main findings.

\section{Publications and Citations of Researchers - Literature Review}

Recent research activities present the importance of publication activity of excellent researchers and research teams. Numerous publications have covered topics related to P/C activities, cooperation in research and similar issues. The majority of them focus on some specific segments. Besides more general work, (e.g., Althouse et al., 2009; Balaz and Jeck, 2018; Braun et al., 1990; Cole and Cole, 1971; Di Vaio et al., 2012; Card and Dellavigna, 2013; Gibson et al., 2017; Leydesdorf, 2008; Hamermesh and Pfann, 2012; Narin and Hamilton, 1996; Anauti et al., 2020; Ioannidis et al., 2018; van den Besselaar and Sandström, 2015; Sandström and van den Besselaar, 2016; Bosquet and Combes, 2013); there 
are publications that use the ESI database. Many of them assess the situation in one country (e.g., Onyancha, 2020; Gautam, 2017; Fu et al., 2011; Miyairi and Chang, 2012; Fu et al., 2011; Allik, 2008; Pislyakov, 2011; Bornmann et al., 2017; Kharabaf and Abdollahi, 2012), others compare more countries (e.g., Almeida et al., 2009; Jeenah and Pouris, 2008; Hu and Rousseau, 2009; Almeida et al., 2009; Zavadskas, 2011). Some studies focus on certain scientific disciplines (Sun and Yuan, 2021; 2020a; 2020b; 2020c; Yuan and Sun, 2019; Liao et al., 2019; Chen et al., 2018; Chuang et al., 2011; 2013; Qin et al., 2020; Ma et al., 2020; Cui, 2020; Zhai and Di, 2019; Yuan and Sun, 2020) or specific scientific or educational institutions (e.g., Cao et al., 2010; Pouris, 2007; Ghane et al., 2013; Gautam, 2015; Huang et al., 2006; Markusova et al., 2009; Aversa and Markusova, 2010; Huang and Chang, 2005; Wang et al., 2011; De Filippo et al., 2017; Cao et al., 2010; Shuang et al., 2016; Mokhnacheva and Kharybina, 2011). Several authors bring a new perspective on specific topics (Viiu and Paunescu, 2021; Colliander and Ahlgren, 2011; Wang et al., 2019; Zhou, 2021; Chen et al., 2021; Hu, 2007; Allik et al., 2020a; 2020b; Lu and Feng, 2009; Csajbok et al., 2007; Galvez, 2018; Allik, 2013; Kremer and Marx, 2009; Zhang et al., 2009; Yang et al., 2020; Liu and Rousseau, 2010; Prathap, 2010; Yu and Xu, 2019). With regard to the limited space, we summarize the results of these works into several points:

- Comparative studies usually conclude that less developed countries (such as some African, Eastern European or Asian countries) lag behind the most developed countries in all or some areas. In some cases, it is stated that some countries or universities have relatively good results in certain segments due to their specialization in the given area.

- Some new approaches are presented either in the use of new indicators or new forms of graphic displays. A hybrid clustering method combining crosscitation and textual analysis is applied in Zhang et al. (2009) to cluster more than 8,000 journals covered in the WoS $(2002-2006)$. For example, Wan et al. (2017) and Zhang et al. (2018) in their studies, based on the ESI database, analyzed 2140 HCPs in the field of Economics and Business from 4499 authors, 914 universities, and 64 countries/territories. The results show that the USA is the global leader with 1517 HCPs, $60.5 \%$ of the top scientists, and $74 \%$ of the most influential universities. The study of Zhang et al. (2018) found that: the collaboration network among the top 76 scientists is not very close, all 50 most influential universities are inter-connected, and the collaboration network among the most influential countries is quite close. This study demonstrates that significant positive correlations exist between authors' HCP and h-index, between universities' HCP and h-index, and between countries' HCP and h-index. Quite often works are presented with primary goal to point out the (un)suitability of using various 
indicators to compare the performance of countries, universities or individuals. Similar to the definition of ESI highly cited papers, Wang et al. (2019) develop a new measure of papers' scientific impact. Works using clustering and graphical representation of similarities and differences in performance are relatively abundant. A hybrid text/citation-based method is used by Janssens et al. (2009) to cluster journals covered by the WoS database in the period $2002-2006$. They use this clustering to improve existing journal-based subject-classification schemes. The choice of 22 clusters allows them a direct field-to-cluster comparison.

- Overall, contributions focused on certain segments dominate (selected countries or groups of countries, specific fields in which $\mathrm{P} / \mathrm{C}$ are monitored, selected journals in which citations are monitored, etc.).

- The mentioned articles bring new perspectives on individual aspects of the issue of measuring the results of scientific work in the (inter)national context. These are new quantitative and qualitative analyzes, new and modified approaches in comparison and new forms of visualization of results. Compared to our article, they usually work with much less data and different sets of variables.

- There are studies that have similar focus that is addressed here - Ioannidis et al. (2018), Small (2004), and Chuang et al. (2013). The main conclusions of Chuang et al. (2013), who focused on the field of chemical engineering, are: the most highly cited ESI papers had fewer authors and were more likely to be single-country papers. A survey of authors of HCPs in 22 research fields was undertaken by Small (2004) in connection with ESI. Authors were asked to give their opinions on why their papers are highly cited. They generally responded by describing specific internal technical aspects of their work, relating them to external factors in their fields of study. A co-occurrence analysis of the dimensions revealed that interest, the most socially based dimension, was most often paired with one of the other more internal dimensions, suggesting a synergy between internal and external factors.

- Using new metrics based on online attention, the Altmetrics, as a reference, Moral-Munoz et al. (2019) offer an overview of the social media attention of the HCPs. A match between the 148,767 WoS documents and their Altmetrics scores $(94,147$ records) was performed. The analysis shows that Twitter is the leading social platform in which the HCPs are disseminated. The analysis also indicated that there are research fields with higher social attention.

Cross-field comparison of citation measures of scientific achievement or research quality is severely hindered by the diversity of the stage of development and citation habits of different disciplines or fields. Based on the same principles of RCR (Relative Citation Rate) and RW (Relative Subfield Citedness), a new dimension - the Relative Superiority Coefficient (SC(n)) in research quality was 
introduced in $\mathrm{Hu}$ (2007). This can indicate clearly the relative research level for research groups at multiple levels in the respective field by consistent criteria in terms of research quality. Comparison of the SC (n), within or across 22 broad fields among five countries, was presented.

Among common scientometric indicators are the number of publications, average citation per document, $h$-index and the number of authors. There are some other possibilities for analysis and comparisons made with data from the SciVerse Scopus or Thomson Reuters ISI WoS database. There are several various databases and sub-databases. Only Thomson Reuters's provides eight sub-databases for its WoS Core Collection: A\&HCI, BKCI-S, BKCI-SSH, CPCI-S, CPCI-SSH, ESCI, SCI-Expanded and SSCI (for details see, e.g., Hu et al., 2020). The various Research Assessment Measures (RAMs) are defined and analyzed in various publications (see Table 3 in the Appendix), but there are some limitations for their use. Chia-Ling et al. (2011) highlight the similarities and differences of the alternative RAM. They find that several RAM capture similar performance characteristics for the leading econometrics and statistics journals, while the new PI-BETA criterion is not highly correlated with any of the other RAM, and hence conveys additional information regarding RAM. It is reported that women are vastly under-represented in the group of MPRs (van den Besselaar and Sandström, 2017). Shekofteh et al. (2016) aims at determining these indicators in first-grade universities of medical sciences in Iran and investigating the correlation among $Y$-index and other indices, and comparison between $Y$-index ${ }^{2}$ and $h$-index. They found a significant positive relationship among $Y$-index with the number of publications, the number of authors, and $h$-index. This indicates that $Y$-index can be a potential proper index, for qualitative and quantitative evaluation of universities along with other research institutions.

One analysis has shown that those more inclusive teams - with a score of one on the Gender Diversity Index (GDI) - tend to perform better and generate more research output. When controlling for gender stereotypes, gender balance and the representation of women within teams, a score of 1 on the GDI is associated with an increase of 0.91 FAP (Field Adjusted Performance) This means that more inclusive teams perform on par with teams that have and additional 0.91 publishing senior researchers. However, there is no statistically significant effect on the quality rank of the published research (GDI, 2018). De Filippo and Sanz-Casado (2018) analyze scientific publications of international prestige in three social science disciplines (communication, economics and sociology) to identify possible production patterns. Emphasis is placed on the study of impact and visibility.

\footnotetext{
${ }^{2} Y$-index is also an indicator considering both the quantity and quality of scientific products, based on first author and corresponding author publications.
} 
They show that social sciences have long been struggling with quantitative forms of research assessment due to insufficient coverage in prominent citation indices and overall lower citation counts than in other subject areas (Lemke et al., 2019).

Research outputs in the Social Sciences and Humanities (SSH) get a much smaller fraction of citations than other disciplines do. The same is true concerning coverage in multidisciplinary bibliographic databases, like the WoS and Scopus. Unfortunately, research assessment exercises and rankings still heavily rely on these databases as well as on citation-based indicators. This results in a nonsatisfying representation of SSH outputs and a hesitant attitude of SSH researchers towards any kind of quantitative evaluation. However, peer-review has also reached its limit in all disciplines due to the exponential growth of research output, increased multi-disciplinarity and a comparatively reduced number of appropriate peers. Furthermore peer-review in SSH is sometimes considered not as rigorous as in the Sciences. The Open Science movement and alternative metrics are currently gaining momentum and offer opportunities to think outside the box of the citation-cantered "publish or perish" system (Frontiers, 2019).

Inter-disciplinarity emerges as a double-edged process and thus "specialization-fragmentation-hybridization" all come together (Sanz-Menéndez et al., 2001). Various aspects determine the greater or lesser importance of interdisciplinary research. Organizational setting of the research, source and extent of financial support and contrasting values of applied investigations and basic research. Three dimensions of a research undertaking are relevant to multidisciplinary team research are: (1) the number of researchers doing the research; (2) the kind of action involved in the research project; and (3) the number of disciplines involved in the research (Blackwell, 1955).

\section{Research Issues and Methodology}

This paper contributes to understanding of research activities by examining publishing activities and citing results of global MPRs. The global list of experts includes the top 88,653 individuals from the world who are listed in a ranking according to several categories. Namely, we have four main categories - WoS publications total (WoSPT) Top publications total (TOPP), Citations per publication (CITP), and Citations total (CIT) plus three additional indicators: WoS publications per researcher (WoS PPR), Top publications per researcher (TPPR), and Citations per researcher (CPR). Our focus is on those experts who are reporting the best results either in terms of quality (measured by citations per publication) or quantity (the number of publications published). The data used in this paper comes from the bibliographic database WoS's ESI, which provides information 
about the MPRs. The database provides data about the publications and citations in various research fields. One of the most important reports is the highly cited papers (HCPs) category that shows the Top $1 \%$ of papers cited in the 22 research fields. The methodology involved analyzing authors of publications published globally in the various fields of science based on conceptual modeling, quantitative data analysis and content analysis of expert interviews. The database contains 88,653 researchers. The data allow us to analyze specific characteristics that are not in standard OECD/Eurostat/World Bank and national statistics databases. Moreover, this database permits us to use selected indicators for better understanding of the top-level researcher activities on global scale.

In recent publications (e.g., Ioannidis et al., 2018), experts find that MPRs outperform their lower-ranked colleagues substantially. They outperform them not only in the total number of publications category, but also in the category of mostly cited publications. Our findings support the idea that "the winner takes it all" phenomenon - widely emerging in various areas of social activities - exists also in research, stressing that current P/C distribution patterns promote MPRs to publish more high-quality papers and to attract more citations than do other researchers.

Without denying the relevance of other factors, our aim is (1) to analyze the link between publication and citation activity and to provide evidence regarding the extent to which MPRs' scientific results are better than scientific results of others. Our second aim (2) is to analyze the kinds of patterns that are occurring in P/C activities of MPRs. Concerning the P/C activity of researchers, we expect that their excellent outputs are likely to be result of characteristics of researchers (their expertise) and the area and focus of research itself rather than of broader conditions affecting their work. The best results can be expected within categories „quantitative top“, and „qualitative top“ researchers. Whereas the former category represents those individuals that exhibit the highest number of published publications or top publications and citations, the latter category represents those reporting the highest number of citations per one publication published. Finally, we briefly analyze differences and pattern across 22 research fields.

\section{Database and Descriptive Statistics}

We used cumulative data on researchers publishing in various areas of scientific disciplines and in various countries during the 10-year plus 4 months period, January 1, 2008 - April 30, 2018. Our full sample represents 88,653 individuals from all countries having internationally accepted researchers. All researchers included have at least 475 citations and at least 1 publication in a WoS journal. 
In order to make our analysis more structured, we used the ESI database of all researchers $(\mathrm{N}=88,653)$ belonging to one of the four indicators and sorted them by the best results for all four indicators (citations per paper, top publications, WoS publications total and citations total). We then made a selection of researchers from the full sample (dataset) and created various sub-samples (see Section 3 for details). We have generated a sample of 354,612 unique data on $\mathrm{P} / \mathrm{C}$ activity divided into four panels. Publication/citation panel sizes are identical. These panels contain 88,653 observations (see Table 1 for descriptive statistics on the sample). Control for missing values has been made in the initial phase, but this process has not significantly affected the number of observations. The ESI database is one of the few datasets providing large-scale comparable data on the $\mathrm{P} / \mathrm{C}$ activity of the academic researchers. While some macroeconomic data are available for publication from OECD databases, they are not specific to the data we require.

In order to better assess the relationship between top publications and publications total we also have constructed a set of sub-samples for these indicators, which serve to show specific pattern of researchers activities. The Table 1 reports the number of researchers included in the sample. The full sample (FS) is further divided into several sub-samples: A, B, C, and D. Selected limit lines are FS $(\mathrm{N}=88,653), \mathrm{A}=$ top $100 ; \mathrm{B}=$ top 2,$000 ; \mathrm{C}=$ top 50,000 , and $\mathrm{D}=$ the lowest $10,000(78,654-88,653)$. The sub-sample $\mathrm{D}$ makes possible to analyze parameters of those "less successful" researchers in our complete sample of the most successful scientists. We see that MPRs - in terms of number of publications show, on average, the highest citation per paper and maximum value of top publications. Conversely, both those with WoS publications only or with low level of citations consistently show the lowest ranking.

Besides the individual cases presented in the Graph 1, 2, and 3, we analyze the differences between the sub-sample "top researchers" (the sub-sample A), full sample, and the other sub-samples (B, C, D). In this case, specification of the top researchers covers top 100 researchers and separate publications into 2 groups: WoS publications total and top publications. The latter ones represent publications with a higher ranking relative to the ranking of standard WoS publications. The summary statistics are computed for the FS and four of its sub-samples. To deliver broader explanation for the reasons behind such differences we are using some additional information based on literature survey and other sources (e.g., interview database). We take a first step by examining the proportion of research conducted among top researchers within certain time period and compare the extent to which they differ in their propensity to be involved in top output levels. In addition to this, we provide comparison of situation as is seen between top 
researchers (the sub-sample $\mathrm{C} ; \mathrm{N}=$ top 50,000) and the lower top sub-sample $\mathrm{D}$ $(\mathrm{N}=$ the lowest 10,000).

One specific limitation is that country affiliation and nationality of researchers are missing due to the construction of the database. The other limitation is that co-authorships linkages are missing as such a linkage is not possible to identify from databases used. Another, maybe "traditional", limitation is that ESI databases are biased in favor of English-language journals and therefore omitted/ undervalued are scientific results occurring in countries with a substantial share of publications published in other language than English ("foreign-language publications"). Our data, however, allow us to analyze the relations based on several characteristics of the researcher. One characteristic analyzed in the paper is whether the researcher having high number of WoS publications has also high number of top publications or whether he has a high number of citations per paper.

T a ble 1

Data for the Samples Used in the Analysis Related to the Publication/Citation Activities

\begin{tabular}{|l|c|c|c|c|c|}
\hline \multirow{2}{*}{$\begin{array}{l}\text { Indicator } \\
\text { total/per } \\
\text { researcher) }\end{array}$} & \multicolumn{5}{|c|}{ Publication or citation activity (number of cases) } \\
Sample size
\end{tabular}

Source: Own computations.

Researchers from full sample ( $\mathrm{N}=88,653$ MPRs ranked according to the number of citations) have 289.13 WoS PPR; from sub-sample A have 18,028.97 WoS PPR; from sub-sample B have 3,554.74 WoS PPR; and from sub-sample C have 459.36 WoS PPR. The lowest 10,000 in our sample (sub-sample D) indicates an average value only $43.30 \mathrm{WoS}$ publications per researcher. TPPR indicator exhibits similar patterns: $\mathrm{FS}=88,653$ researchers have $9.46 \mathrm{TPPR} ; \mathrm{A}=$ top 100 have 284.63 TPPR; $\mathrm{B}=$ top 2,000 have $69.45 \mathrm{TPPR}$; and $\mathrm{C}=$ top 50,000 
have 14.77 TPPR. The lowest 10,000 in our sample have only 1.59 top publications per researcher. Finally, two other indicators (citations per paper - CITP - and citations per researcher - CPR) show similar patterns: FS data are CITP 22.72/CPR 6570.83; $\mathrm{A}=$ top $100(13.25 / 238,994.51) ; \mathrm{B}=$ top 2,000 (15.65/55,624.88); $\mathrm{C}=$ top $50,000(22.51 / 10,338.47)$ and the lowest 10,000 sub-sample $\mathrm{D}$ has the value of indicators $19.48 / 843.57$. The top 10 researchers produce about $1.62 \%$ of all WoS publications and $0.73 \%$ of all Top publications published by the full sample group and receive about 13.25 CITP (but 238,994.51 CPR) whereas the full sample researchers have on average 22.72 CITP, but much less citations per researchers 6570.83 .

Table 1 provides information regarding the outputs of the top of world researchers, based on selection by four indicators. The data show that maximum values for WoS, CIT, CITP and TOPP are 52,278/663,490/10,586, and 798, while minimum values stay at $1 / 475 / 0.32$, and 0.00 . This means that there are some differences across the whole sample. In all four categories, the results show that the top researchers have much better results than the rest of the sample. Note that the summary statistics reported in Tables 1 and 2 do not account for additional factors (e.g., age, type of affiliation, specifics of activities, and country of origin researchers) that are likely to affect the propensity to reach top results. We will address certain specific factors in detail in the Section 5 where some specific data are available for this kind of analysis.

Number of citations per paper is mentioned in the database. We prefer to use this indicator because we consider ,per paper" indicator, as a sign of quality, more important than total number of publications. One exception is the "top publications" category because here is implicitly contained quality aspect - i.e., a journal where such papers appear occupies the highest qualitative rank among journals. All researchers included have at least 475 citations and at least one publication in a WoS journal. A number of researchers in the lower end (partly covered by the sub-sample D) have an extremely low number of (top) publications and/or citations. Particularly notable is the extreme case of zero paper per researcher for the total number of 6,022 researchers or one paper per researcher $(11,266$ researchers). Similar situation applies for citations and other parameters analyzed within sub-sample D. Top ten of the best performers have an average of 618.8 TPPR (top publications per researchers).

The most productive researchers also vary in the level of diversity of P/C, measured by the percentage of top researchers of the top indicator results. Researchers, which exhibit the highest rate of publications published, also have a very high concentration of citations in some publications due to the substantial impact of some of their scientific output on global science community. Other researchers (such as those from sub-sample D) show a more diversified composition of $\mathrm{P} / \mathrm{C}$ score. 


\section{Distribution of Publication and Citation Activity of Top Researchers}

In the analysis that follows, analyzed MPRs are classified into one of four categories with respect to their excellence in terms of quality and quantity. The four categories are: (1) the best "top class" researchers (sub-sample A; top 100 of the FS); (2) excellent researchers (including "top" researchers category; subsample B; top 2,000); (3) very good researchers (including the previous two categories; sub-sample C; top 50,000); and "lower end" researchers (sub-sample $\mathrm{D}$; the lowest 10,000 of the FS). Based on the database data, we derive two measures of the individuals chance to have an excellent $\mathrm{P} / \mathrm{C}$ records using two alternative types of information: (a) the number of citations, and (b) characteristics of the researcher in terms of whether it shows higher than average number of citations per paper.

The Graph 1 depicts distribution of data collected regarding WoS, CIT, CIT/P and TOPP indicators. In this case, each indicator relates to individual category scale to see scale of particular distributions within the four categories displayed. The data sample here shows complete database representing 88,653 observations.

Graph 1

Numbers of WoS, CIT, CITP and TOPP (individual category scale, $\mathrm{N}=88,653$ )

\begin{tabular}{|c|c|c|c|c|c|c|c|}
\hline & WOS & & $\mathrm{CIT}$ & & CITP & & TOPP \\
\hline 60,000 & & 700,000 & & 12,000 & & 1,000 & \\
\hline 50,000 & * & 600,000 & $\begin{array}{l}* \\
*\end{array}$ & 10,000 & 粪 & 800 & * \\
\hline 40,000 & $\begin{array}{l}\text { 粪 } \\
\text { t }\end{array}$ & 500,000 & $\begin{array}{l}\text { 粪 } \\
\text { 米 }\end{array}$ & 8,000 & * & & \\
\hline & * & 400,000 & * & & * & 600 & 業 \\
\hline 30,000 & 样 & 300,000 & 業 & 6,000 & & & 粚 \\
\hline 20,000 & & 200,000 & & 4,000 & & 400 & 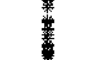 \\
\hline 10,000 & & 100,000 & & 2,000 & & 200 & \\
\hline
\end{tabular}

Values for the indicators in the Graph 1 (WoS, CIT, CITP, and TOPP) show that the frequency of observations decreases with increasing values. For example, in the case of the indicator total number of citations, only three authors report over 600,000 citations. In the case of CITP indicator, only two publications have more than 10,000 citations. Only one author has more than 50,000 publications $(52,278)$. Only two authors have about 800 papers in the best journals. A specific form of co-authorship of large international teams often generates high number 
of publications, where many co-authors are mentioned. The Graph 2 shows graphically distribution of individual categories analyzed.

The Graph 2 covers similar situation, as in the previous case. The only difference here is in the size of the sample, which is reduced to top 2,000 cases. Ranking in this case reflects the number of citations. In this graph are depicted those 2,000 researchers who have the highest number of citations (CIT). In order to investigate the link between Publications total/Top publications/Citations total/Citations per paper, we present data in Table 2 concerning the various samples analyzed. Top 50,000 sample and FS (columns IV and I) represent top class of researchers whereas Top 100 and Top 2,000 form a superclass (column II and III). There are, however, important exceptions: in the case of top publications, which attract a large number of top researchers, we observe a relatively smaller share of citations per paper. When we restrict the analysis to a sub-sample of 2,000 researchers only, and in the case of CITP and Top publications, we actually see an increase. The data also allow us to analyze the relationship between publications and citation by looking at the tendency that the top publications have a propensity to attract more citations than other publications.

Graph 2

Distribution of Individual Categories Analyzed - WoS, Cites, Cites/Publication (CITP) and Top Publications ( $\mathrm{N}=$ Top 2,000)

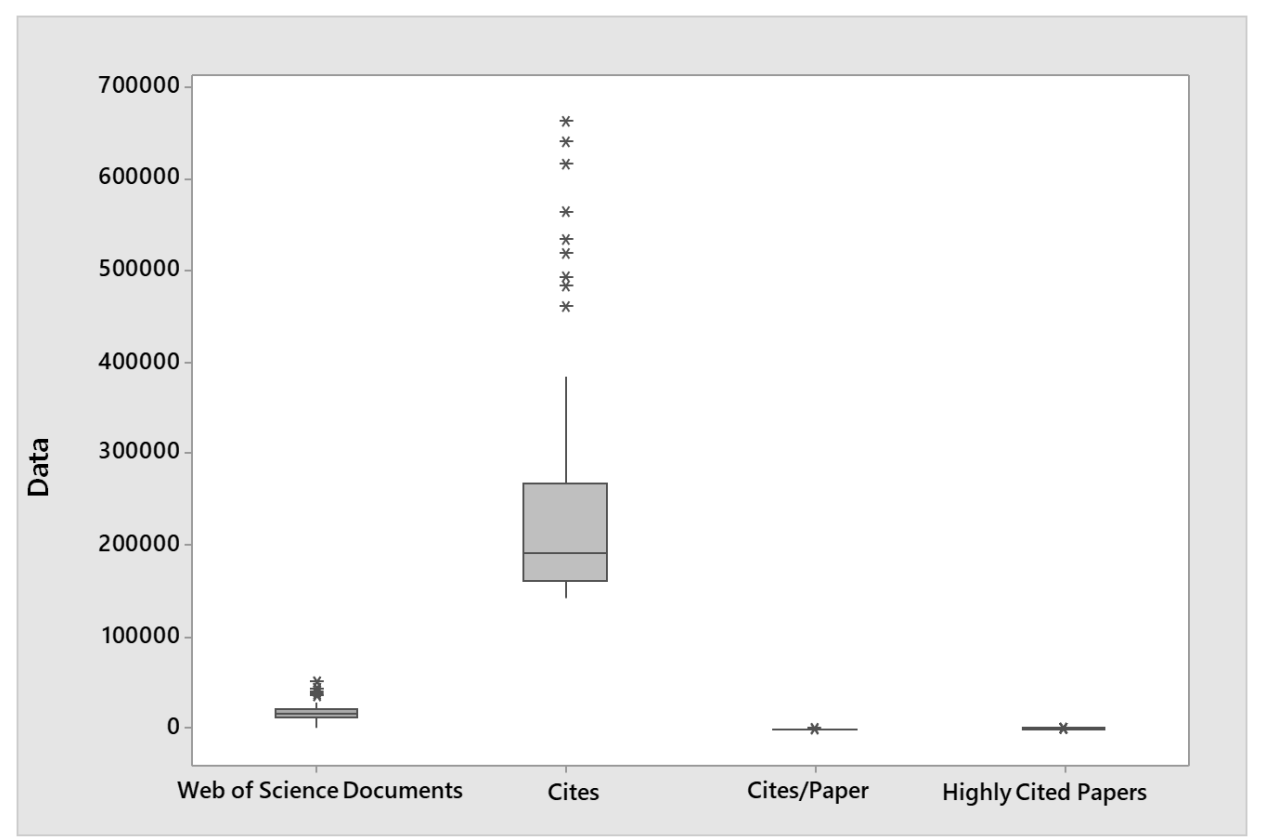

Note: Top papers are descripted here as Highly Cited papers.

Source: Own computations. 
It is possible to see that there are clusters of most typical values of performance with, e.g., extraordinary small cases for some extreme values as is in the case of cites.

\section{Analysis of Publication/Citation Activity of Top Researchers}

This section presents a set of cases that analyze the situation of a correlation at the individual level between publications and top $\mathrm{P} / \mathrm{C}$ of international sample of top researchers. It is important to see whether the particular researcher reported high number of publications simultaneously with high level of citations per publication or not (presence of the excellence effect). Our analysis, as mentioned above, includes a set of scientific result characteristics. In particular we study top publications (TOPP), WoS publications (WoS PUB), citations total (CIT TOT) and citations per publication (CITP). We also analyze in "all case specifications" a set of features characterizing $\mathrm{P} / \mathrm{C}$ activity.

Here we present our results of a model testing for the presence of significant relations at the individual level between the publication activity and the size of the citation activity of researchers (specifically CIT/WoS, TOPP/WoS, and CITP/WoS). We expect improvement of position in publication activity to be linked to citation activity because higher global presence makes MPR more visible to citation opportunities, and more able to overcome "invisibility trap" facing researchers publishing in less known/non-English language publications. Simultaneously, research results are affected not only by individual performance of a researcher, because science is collaborative (not collective) effort, but also by research effort of large international teams.

Given the important role that top publications play in scientific production, we first examine whether top publications are more likely among researchers from sub-sample A. In case A, we look at this issue by differentiating the top publications of researchers from the sub-sample A compared with the situation in the full sample. Results indicate the presence of differentiated effects for the sub-samples available. The sub-sample A (top 100) with a relative higher scientific level outperform the FS dataset as well as sub-samples B, C, and D. For the sub-sample A holds true that the value of "WoS publications per researcher" indicator $(18,029)$ is much higher than values for other categories $\mathrm{FS} / \mathrm{B} / \mathrm{C} / \mathrm{D}$ (289.1/3,554.7/459.4/43.3). Similar observation can be found for other indicators. "Top publications per researcher" indicator has different values for $\mathrm{A} / \mathrm{FS} / \mathrm{B} / \mathrm{C} / \mathrm{D}$ (284.6/9.5/69.5/14.8/1.6). While "citations per researcher" still have expected pattern, where the sub-sample A dominates with 238,994.5 citations per researcher, and other sub-samples and FS follow logical patterns, this is not the case for 
"citations per paper" indicator. Here the best value is found for FS (22.7) and sub-sample $\mathrm{C}$ follows (22.5). The sub-sample A exhibits surprisingly the lowest value (13.3). This fact may indicate that either the Top 100 researchers (subsample A) publish many publications - but many of them are less cited - or quality of their publications is very heterogeneous. We also find their publication and citation performance to be significantly lower than that of researchers from higher level sub-samples. We conclude that, compared to the lower-level subsamples, the excellence effect is stronger in size for the top researchers with high number of publications published. In all cases - except very important "citation per publication" indicator - the top researchers hold an excellence premium over the lower-level MPRs.

The Graph 3 shows distribution of different sets of data and correlation for the full sample category $(\mathrm{N}=88,635)$.

Graph 3

Correlation between CIT/WoS, TOPP/WoS, CITP//WoS (full sample: $\mathrm{N}=88,653$ )
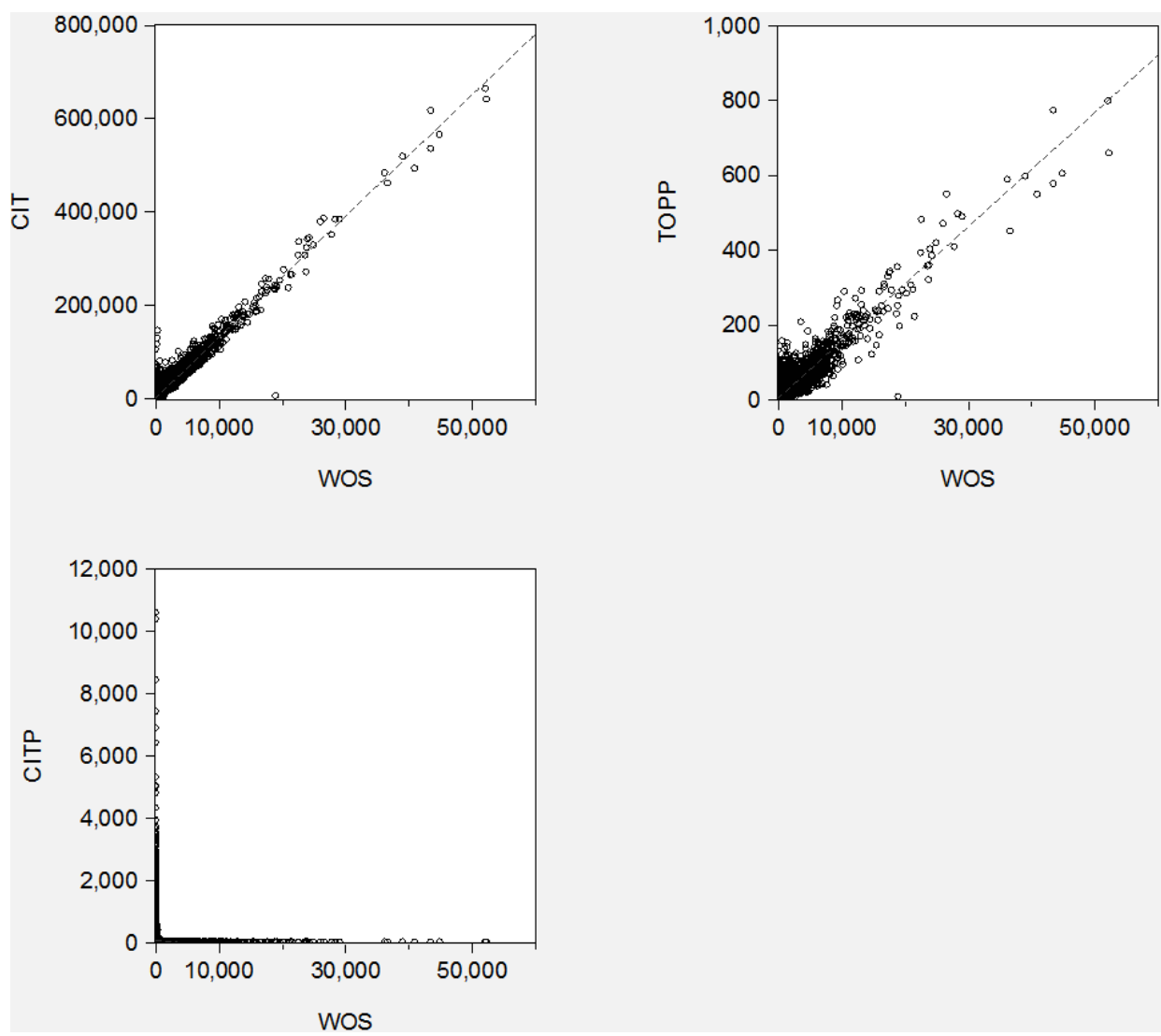

Source: Own computations. 
Graph 4

Correlation between Several Indicators of Publication and Citation Activity -

CIT/WoS, TOPP/WoS, and CITP/WoS. Left: Sub-sample C ( $=$ top 50,000);

Right: Sub-sample D ( $\mathrm{N}=$ the lowest 10,000)
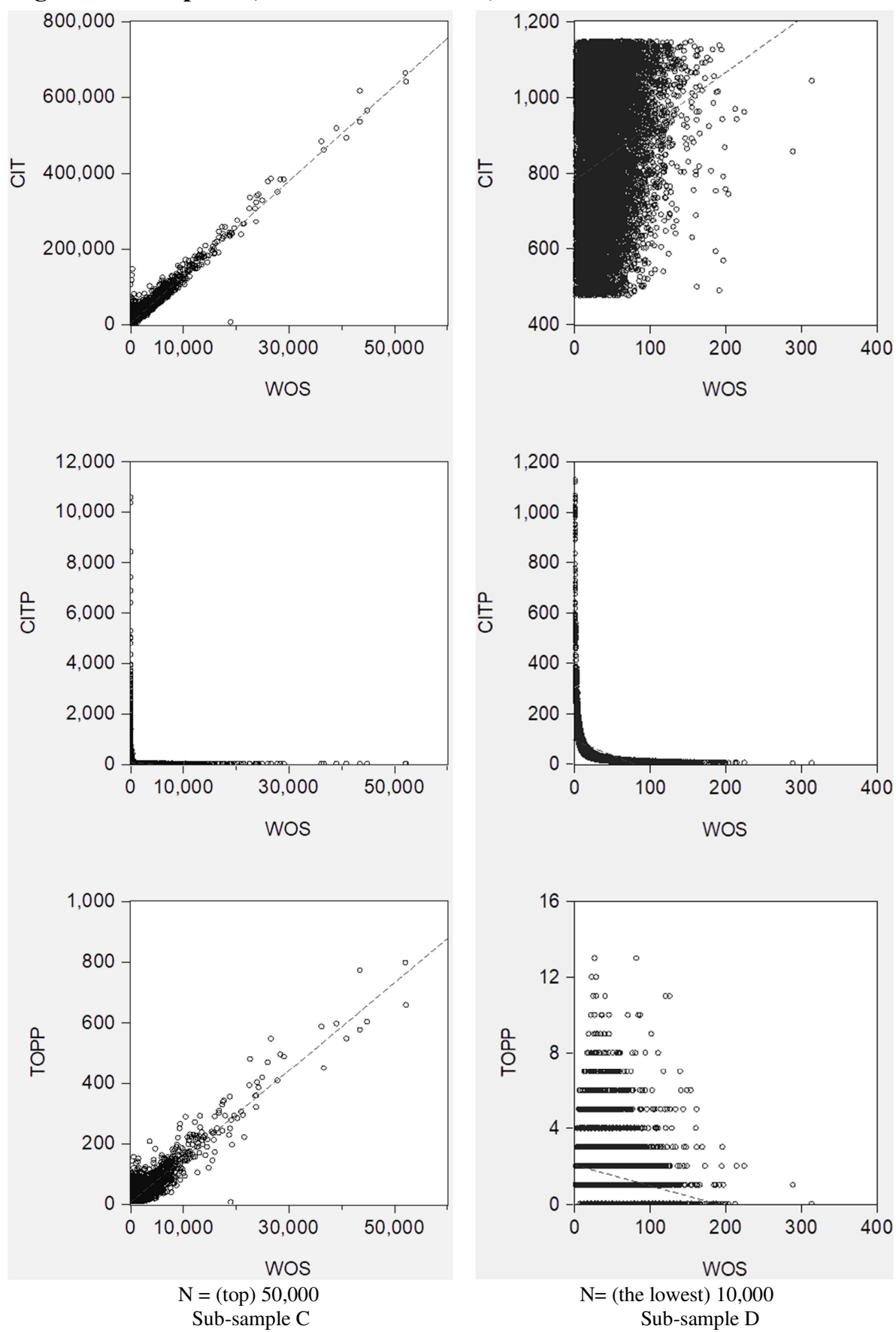

Source: Own computations. 
In the Graph 4, we analyze the correlation between pairs of variables CIT/WoS, TOPP/WoS, and CITP/WoS for two sub-samples $\mathrm{C}(\mathrm{N}=$ top 50,000, left hand side) and $\mathrm{D}(\mathrm{N}=$ the lowest 10,000 , right hand side). Here we split the publication/citation activity according to its ranking.

The sub-sample specifications are reported in the Table 1 (individual sub-samples represent restricted samples in which we analyze different layers of researchers). We do so in order to demonstrate scale differences between top researchers and the "lower top" ones. The Graph 5 illustrates substantial differences between the two sub-samples depicted.

In addition to correlation analysis described, the regression analysis made shows the results of fitting a linear model to describe the relationship between Cites and WoS (Model A), and Cites and Top publications (model B). The equation of each individual fitted model is as follows:

Model A: $\quad$ MOD- $A_{\text {Cites }}=2818,68+12,9777 *$ MOD-A $A_{W o s}$

Model B: $\quad$ MOD- $\mathrm{C}_{\mathrm{Cites}}=306,776+661,784 *$ MOD- $\mathrm{C}_{\text {Top publications }}$

Since the P-value is less than 0.01 in each case, there is a statistically significant relationship between Cites and WoS (Mod A), and Cites and Top publications (Mod B) at the 99\% confidence level. The R-Squared statistic indicates that the model as fitted explains $85.8 \%$ of the variability in Cites (Mod A), and $84.3 \%$ of the variability in Top publications (Mod B). The correlation coefficient equals 0.926419 (Mod A), and 0.918179 (Mod B), indicating a relatively strong relationship between the variables. The standard error of the estimate shows the standard deviation of the residuals to be $4639.2(\operatorname{Mod} A)$, and $4881.63(\operatorname{Mod} B)$. Tests for regressions are performed for two pairs of variables (see Tables II and III in the Appendix). Relatively higher chances to be cited have those researchers with higher number of publications and this applies especially for those in the upper group. Intuitively, it can be assumed that the more publications MPRs have, the more citations they receive. The question is whether this also applies to top publications or only to publications as a whole. Authors of publications with more citations have higher quantity of publications, but those researchers with the highest number of publications published have comparatively lower number of CITP than is the average for the full sample. In the case of the highest number of publications per researcher, the number of CITP is quite low (only rarely exceeding 10 citations per paper). The best-cited publications have those researchers exhibiting low number of total publications.

We further analyze this relations by assessing the impact of CITP from all other sub-samples, be they sub-samples with the WoS PUB or sub-samples with Top publications. The variable capturing $\mathrm{P} / \mathrm{C}$ activity with other than the top group (WoS PUB) is also positive and significant although significantly smaller 
than the non-WoS PUB coefficient. The significant effect is likely caused by the inclusion of respondents who report publishing only with the best journals and not in the WoS PUB. The relatively small size of the coefficient is likely caused by the fact that the former group of researchers makes up a minority of those in this category. To investigate this further, we differentiate the publications between „normal“ WoS publications and „top“ publications. The variable WoS PUB, capturing better standard quality publications, is highly significant. In conclusion, we show that, among researchers with extremely high values of individual indicators there is only a few who reach top levels. Both the publication in the top journals and the top citations matter, but researchers who exhibit those results appears to have no formal advantage compared to the non-excellent researchers.

Graph 5

Surface Plot of “WoS Documents" vs. "Citations” vs. "Highly Cited Publications"

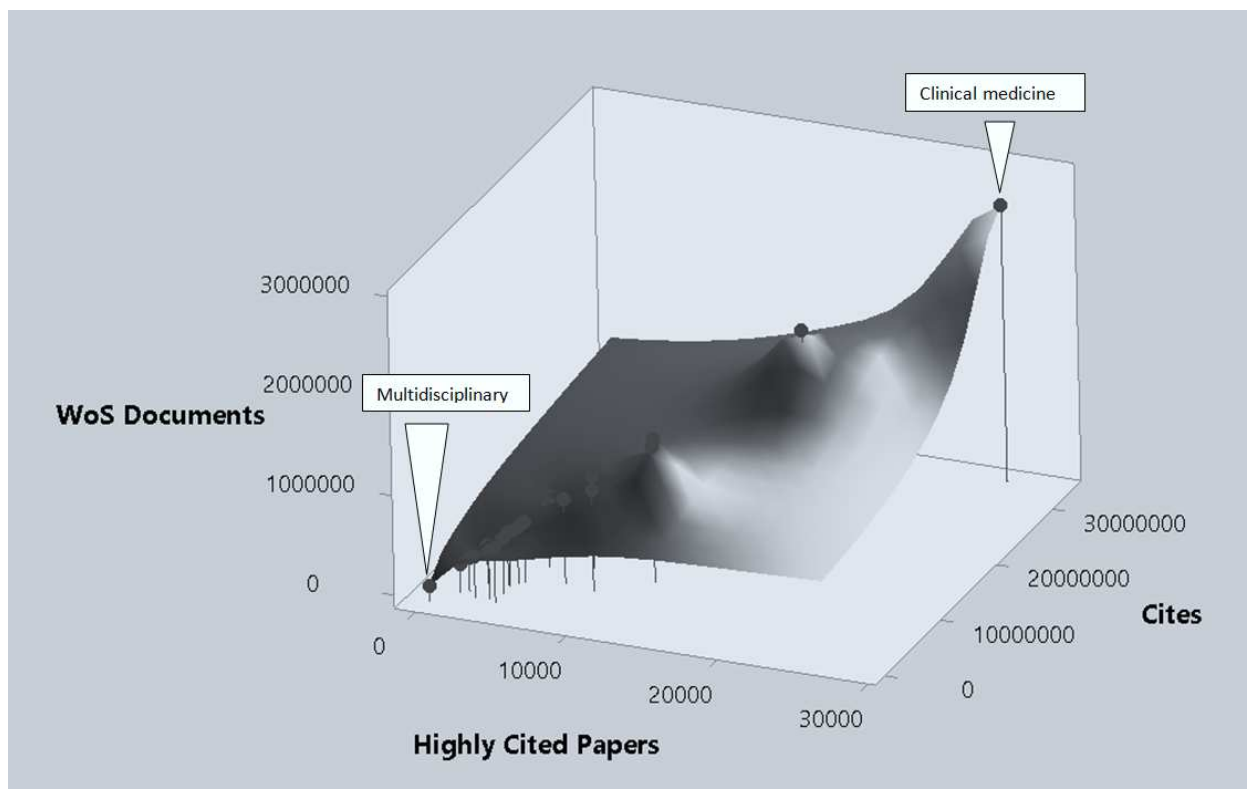

Note: Data used represent 22 individual Research Fields - (1) Clinical Medicine; (2) Chemistry; (3) Physics; (4) Biology and Biochemistry; (5) Molecular Biology and Genetics; (6) Material Science; (7) Engineering; (8) Neuroscience and Behavior; (9) Plant and Animal Science; (10) Social Sciences, General; (11) Environment/Ecology; (12) Geosciences; (13) Pharmacology and Toxicology; (14) Psychiatry/Psychology; (15) Immunology; (16) Agricultural Sciences; (17) Microbiology; (18) Space Science; (19) Computer Science; (20) Economics and Business; (21) Mathematics; (22) Multidisciplinary. Identification of position in the Graph has been made for (1) and (22) only.

Source: Own computations.

Looking at the differences across various research fields reveals differences of miscellaneous types. What has been observed so far is the fact that in social sciences the number of citations for the top papers as well as for the best researchers 
is substantially lower than in some other research fields. One example supporting this contention is the Table 6 in the Appendix. It shows rather smaller values for the most cited papers in economics (the maximum value is 6,231 cites) compared with median and mean values for the full sample $(3,350$ and 6,571 cites, respectively).

The Graph 5 shows a surface view of the above-mentioned differences. The clinical medicine research field is the area of research with the largest number of published WoS documents (2.6 million), the highest number of citations (33.2 million) and 26.4 thousand highly cited publications. Multidisciplinary sciences show significantly lower values (20.6 thousand documents, about 300 thousand citations and only 201 highly cited publications). The only important similarity in both research fields is an average number of citations per paper, which is 12.6 for clinical medicine category, and 14.5 for multidisciplinary science category.

\section{Some Factors Contributing to Excellent Publication/Citation Performance}

One of the factors explaining higher level of citation is migration. Physicists who moved between countries for their work received $17 \%$ more citations than their stay-at-home counterparts. Their publications also covered a wider range of topics and had more co-authors. Alex Petersen (Science, 2018) looked at 26,000 physicists with papers published in journals of the American Physical Society between 1980 and 2009 and examined how their performance changed over the decade that included a move. To account for the possibility that scientists who are stronger performers get more chances to move, Petersen's study design paired mobile scientists with non-mobile scientists whose scientific accomplishments were otherwise similar. The study is one of several in recent years finding that cross-border mobility among scientists helps boost their research performance (Science, 2018).

Besselaar and Sandström (2015) used a dataset consisting 48,000 researchers and their WoS publications during 2008 - 2011 period with citations until 2014 and investigated the relation between productivity and production of highly cited publications. They have made conclusion that quantity makes a difference.

Another explanatory factor for substantial differences among top researchers is that if an expert created or co-created some entity (database, collected biological samples, clinical trial records, formulated standards or concepts) that is often used, then he receives higher number of citations. In this case, such entities are frequently cited. This reflects the changing nature of research work. Nowadays, scientists are less likely to work on problems individually (especially in natural 
sciences), and therefore the evaluation of results is based on the work of research teams, not just individual researchers. We used Ioannidis et al. (2018) and their original database of interviews to find out the possible explanatory factors behind the emerging results in terms of number of citations. For the purpose of this paper, it is not important to look in detail at other explanatory factors, which may include, e.g. granularities. ${ }^{3}$

However, it can be assumed that even such factories can to a lesser extent influence the results of researchers' success. According to Ioannidis et al. (2018) an author should fulfill the following criteria:

- Substantial contributions to the conception or design of the work; or the acquisition, analysis, or interpretation of data for the work, and

- Drafting the work or revising it critically for important intellectual content, and

- Final approval of the version to be published, and

- Agreement to be accountable for all aspects of the work in ensuring that questions related to the accuracy or integrity of any part of the work are appropriately investigated and resolved.

Ioannidis et al. requested e-mail comments from all listed MPRs (defined as authors who have published an average of a paper every five days indexed in Scopus within a single calendar year, period 2000 - 2016), excluding Physics and Chinese/Korean names, in August 2018. They wanted to receive a brief explanation of how those authors fall into this extremely productive class, how they feel about belonging to this class and if they have any other comments. They compiled responses obtained and it formed supplementary file to their Nature paper (Ioannidis et al., 2018). The response was as follows: of the sample of MPRs - 94 researchers responded and 81 provided a comment. Table 6 shows our categories of factors contributing to success of MPRs with some examples provided. These examples are among the most commonly cited in their paper as the causes of success in scientific work.

The main reason for one researchers very large number of publications in one particular year was, e.g., the publication of a major book of which the person was the chief editor. The book format, with over two hundreds of very short publications in total, meant that the researcher was either lead author or a co-author on about sixty of these relatively short papers.

\footnotetext{
${ }^{3}$ Granularity describes the degree of aggregation of the resource to be registered. Depending on discipline or resource, different levels of granularity can be applicable. DOI names can be assigned at any desired degree of precision and granularity that a publisher deems to be appropriate (Helbig et al., 2015; Simons, 2012). Helbig et al. (2015) for the decision on granularity recommend consideration of the following „CUTS“ points (a) current citation and research practices among the user community (Citation); (b) needs of various stakeholders (Use of data); (c) complexity and extent of research data (Type of resource); and (d) maintenance of metadata (Sustainability).
} 


\section{Conclusions}

This paper contributes to an understanding of publication/citation $(\mathrm{P} / \mathrm{C})$ patterns of the globally most productive researchers (MPRs). Data are from the ESI database that collected detailed data on the publication/citation of top researchers. Our research approach has also important strength. The homogeneity and size of the sample studied allows for direct comparisons across individual categories selected. Our summary evidence confirms the heterogeneity of the P/C phenomenon for our sample of the top researchers $(\mathrm{N}=88,653$ individuals with four sub-samples $\mathrm{A}=$ top $100 ; \mathrm{B}=$ top 2,000; $\mathrm{C}=$ top 50,000, $\mathrm{D}=$ the lowest 10,000 ).

Major findings are that top researchers from our sub-samples $\mathrm{A}, \mathrm{B}$, and $\mathrm{C}$ have substantially larger international publication impact than the sub-sample D. The difference as such is less interesting than the fact that there are substantial gaps between top performing researchers and the rest of the MPRs sample. Our research finds that very good researchers have quite different results and the best ones (top researchers) in each category represent only minor part of the full sample. This indicates huge limitation in terms of „massive“ science approach in many countries trying to accelerate their research results by stressing quantitative and financial aspects predominantly. Consistent with the "winner takes it all" phenomenon, our finding indicates possibility that top publications matter to the extent that researchers cite often those researchers with the highest number of publications. There are, however, more additional explanations. Sometime the results of the top researchers are based on their participation in several large teams. Another explanation is that the researchers have professionally raised a number of young colleagues and they have become successful and cite the work of their former mentors. Final explanation here, but not the last one, is that if an expert (co-)created some entity, based on laborious and often long-term research results (databases, collected biological samples, set standards or formulated concepts) that are often used, he/she receives more citations. In this case, such entities are frequently cited. These "explanations" may reflect the changing nature of current research work and different way of looking at the problem. Nowadays, scientists are less likely to work on problems individually, especially in natural sciences, and therefore the evaluation of results is based on the merits of entire teams, not just individual researchers.

We also find that a large share of the MPRs publish excellent publications and receive high number of citations. The best-cited publications have researchers exhibiting low number of total publications. Researchers from full sample have 289 WoS publications per researcher (PPR); sub-sample A has in average 18,029 PPR; sub-sample B has 3,555 PPR; and sub-sample C has in average 459 WoS PPR. The sub-sample D, the lowest 10,000 in our sample, has only $43 \mathrm{WoS}$ 
PPR. Top publications per researcher (TPPR) indicator exhibits similar patterns: full sample researchers have 9.5 TPPR; sub-sample A has 285 TPPR; sub-sample $\mathrm{B}$ has 70 TPPR; and sub-sample $\mathrm{C}$ has 15 TPPR. The sub-sample D has only less than two TPPR. Finally, two other indicators (CITP and CPR) show similar patterns: full sample data exhibit CITP 23/CPR 6571; sub-sample A $(13 / 238,995)$, but sub-sample D has the value of indicators 20/844. While CPR still has expected pattern, where the sub-sample A dominates with 238,994.5, CPR, FS and other sub-samples follow logical patterns, this is not the case for CITP indicator. Here the best value is for FS and sub-sample C follows. The sub-sample A exhibits surprisingly the lowest value (13.3). This fact may indicate that either the top 100 researchers publish many publications, but many of them are poorly cited, or that quality of their publications is very heterogeneous. Results indicate the presence of differentiated effects for individual sub-samples. The sub-sample A with a relative higher scientific level outperforms the FS dataset as well as sub-samples B, C, and D. For the sub-sample A, it holds true that the value of "WoS publications per researcher" indicator is higher than values for other groups FS/B/C/D. Similar observation holds for other indicators. Finally, the researchers who have a relatively better per paper citations have superior results compared to those having less excellent outputs.

Second, we analyze relation between individual categories directly by comparing their values. Our research also shows that researchers with higher number of publications could obtain more citations per paper. We have found, similar to the results of Besselaar and Sandström (2015), a significant relationship between numbers of WoS publications and Cites, and Top Publications and Cites. Tests performed show that relatively higher chances to be cited have those researchers with higher number of publications and this applies especially for those in the upper group. Intuitively, it can be assumed that the more publications scientists have, the more citations they have. The question is whether this also applies to top publications or only to publications as a whole. We have already found that MPRs with more citations have higher quantity of publications, but those researchers with the highest number of publications published have comparatively lower number of CITP than is the average for the full sample. In the case of the highest number of publications per researcher, the number of CITP is quite low (only rarely exceeding 10 citations per paper). The best-cited publications are found for researchers exhibiting low number of total publications. As the nature of science is changing, especially in the natural sciences (global interdisciplinary teams using large-scale databases doing research), there are many P/C. Inter-, multi-, and intra-disciplinarity are features that newly predetermine the nature of research and collaboration of researchers. The higher number of $\mathrm{P} / \mathrm{C}$ among "the 
best" top researchers $(\mathrm{N}=100)$ may be driven primarily by the area of research (working with unique elements, specific expensive experiments and other issues make importance of such research more interesting and valuable than standard results). Such results suggest that researchers performance during observed period is consistent with the other finding that a large share of scientific output and citations comes from top levels of researchers. Another finding is that top publications matter to the extent that top researchers with many $\mathrm{P} / \mathrm{C}$ are clustered in a top group. Final finding is that the number of publications correlates with the number of citations. However, the situation that those researchers at the top of the ranking in one category have also superior position in other ranking is rather rare case in our sample.

Looking at the patterns characterizing 22 research fields reveals differences of miscellaneous types. The clinical medicine research field, for example, is the area of research with the largest number of published WoS documents and the highest number of citations. Multidisciplinary sciences show significantly lower values. The only important similarity in both research fields is an average number of citations per paper, which is 12.6 for clinical medicine category, and 14.5 for multidisciplinary science category.

\section{References}

ALLIK, J. (2013): Factors Affecting Bibliometric Indicators of Scientific Quality. TRAMES Journal of the Humanities and Social Sciences, 17, No. 3, pp. $199-214$. DOI: 10.3176/tr.2013.3.01.

ALLIK, J. (2008): Quality of Estonian Science Estimated through Bibliometric Indicators (1997 2007). [Proceedings of the Estonian Academy of Sciences, 57, No. 4, pp. 255 - 264.] Tallinn: Estonian Academy Publishers. DOI: 10.3176/proc.2008.4.08.

ALLIK, J. - LAUK, K. - REALO, A. (2020a): Factors Predicting the Scientific Wealth of Nations. Cross-Cultural Research, 54, No. 4, pp. 364 - 397. DOI: 10.1177/1069397120910982.

ALLIK, J. - LAUK, K. - REALO, A. (2020b): Indicators of the Scientific Impact of Nations Revisited. Trames - Journal of the Humanities and Social Sciences, 24, No. 2, pp. $231-250$. DOI: 10.3176/tr.2020.2.07.

ALMEIDA, J. A. S. - PAIS, A. C. - FORMOSINHO, S. J. (2009): Science Indicators and Science Patterns in Europe. Journal of Informetrics, 3, No. 2, pp. 134 - 142, DOI: 10.1016/j.joi.2009.01.001.

ALTHOUSE, B. M. - WEST, J. D. - BERGTROM, C. T. - BERGSTROM, T. (2009): Differences in Impact Factor across Fields and over Time. Journal of the Association for Information Science and Technology, 60, No. 1, pp. $27-34$.

ANAUTI, M. V. - GALIANI, S. - GÁLVEZ, R. H. (2020): Differences in Citation Patterns across Journal Tiers: The Case of Economics, Economic Inquiry, 58, No. 3, pp. 1217 - 1232. Available at: 〈http://www.nber.org/papers/w25101.pdf〉.

AVERSA, E. - MARKUSOVA, V. (2010): Bibliometric Indicators and Their Impact on Russian University Rankings. Collnet Journal of Scientometrics and Information Management, 4, No. 1, pp. $1-8$. 
BALAZ, V. - JECK, T. (2018): European Co-operation in Science: Evidence from the European Co-authorship Patterns. Economic and Social Development. [Book of Proceedings.] [35th International Scientific Conference on Economic and Social Development, Lisbon, 15 - 16 November 2018, December 2018.]

BESSELAAR, P. van den - SANDSTRÖM, U. (2015): Does Quantity Make a Difference? The Importance of Publishing Many Papers, October. Available at: $<$ https://arxiv.org/ftp/arxiv/papers/1510/1510.01871.pdf>.

BESSELAAR, P. van den - SANDSTRÖM, U. (2017): Vicious Circles of Gender Bias, Lower Positions, and Lower Performance: Gender Differences in Scholarly Productivity and Impact. PLoS ONE, August 2017. DOI: 10.1371/journal.pone.0183301.

BLACKWELL, G. W. (1955): Multidisciplinary Team Research. Social Forces, 33, pp. 367 - 374.

BORNMANN, L. - BAUER, J. - SCHLAGBERGER, E. M. (2017): Characteristics of Highly Cited Researchers 2015 in Germany. Scientometrics, 111, No. 1, pp. 543 - 545. DOI: $10.1007 / \mathrm{s} 11192-017-2248-7$.

BOSQUET, C. - COMBES, P. P. (2013): Are Academics Who Publish More also More Cited? Individual Determinants of Publication and Citation Records. Scientometrics, 97, pp. $831-857$.

BRAUN, T. - GLÄNZEL, W. - SCHUBERT, A. (1990): Publication Productivity: From Frequency Distributions to Scientometric Indicators. Journal of Information Science, 16, pp. 37 - 44.

CAO, Y. - TONG, H. F. - YU, J. (2010): Overall and by Fields Research Output Evaluation of Chinese Mainland Universities Based on ESI Database. In: ZHU, K. L. and ZHANG, H. (eds): Comprehensive Evaluation of Economy and Society with Statistical Science. Marrickville: Aussino Academic Publishing House, pp. 485 - 494. ISBN 978-1-921712-09-8, 2010.

CAO, Y. - TONG, H. F. - YU, J. - CHEN, D. Z. - HUANG, M. H. - ZHANG, X. - LUO, Y. ZHAO, Y. H. - ZHANG, Z. Y. (2010): Performance Evaluation of Universities in China Based on ESI Database. In: KOCAOGLU, D. F., ANDERSON, T. R. and DAIM, T. U. (eds): Performance Evaluation of Universities in China Based on ESI Database. PICMET 2010: Technology Management for Global Economic Growth. New York: IEEE. ISBN 978-1-890843-22-9.

CARD, D. - DELLAVIGNA, S. (2013): Nine Facts about Top Journals in Economics. Journal of Economic Literature, 51, No. 1, pp. $144-161$.

CHEN, T. - LI, G. P. - DENG, Q. P. - WANG, X. M. (2021): Using Network Embedding to Obtain a Richer and More Stable Network Layout for a Large Scale Bibliometric Network. Journal of Data and Information Science, 6, No. 1, pp. $154-177$. DOI: 10.2478/jdis-2021-0006.

CHEN, Q. H. - GENG, N. - ZHU, K. (2018): Review and Bibliometric Analysis of Chinese Agricultural Economics Research: 2006 - 2015. China Agricultural Economic Review, 10, No. 1, pp. 152 - 172. DOI: 10.1108/CAER-07-2017-0141.

CHIA-LING, CH. - McALEER, M. - OXLEY, L. (2011): Great Expectatrics: Great Papers, Great Journals, Great Econometrics, May 2011. Available at: <https://core.ac.uk/download/pdf/6237204.pdf>.

CHUANG, K. Y. - WANG, M. H. - HO, Y. S. (2013): High-impact Papers Published in Journals Listed in the Field of Chemical Engineering. Malaysian Journal of Library \& Information Science, 18 , No. 2 , pp. $47-63$.

CHUANG, K. Y. - WANG, M. H. - HO, Y. S. (2011): High-impact Papers Presented in the Subject Category of Water Resources in the Essential Science Indicators Database of the Institute for Scientific Information. Scientometrics, 87, No. 3, pp. $551-562$. DOI: 10.1007/s11192-011-0365-2.

COLE, J. - COLE, S. (1971): Measuring the Quality of Sociological Research: Problems in the Use of the Science Citation Index. The American Sociology, 6, February, pp. 23 - 29.

COLLIANDER, C. - AHLGREN, P. (2011): The Effects and Their Stability of Field Normalization Baseline on Relative Performance with Respect to Citation Impact: A Case Study of 20 Natural Science Departments. Journal of Informetrics, 5, No. 1, pp. 101 - 113. DOI: 10.1016/j.joi.2010.09.003. 
CSAJBOK, E. - BERHIDI, A. - VASAS, L. - SCHUBERT, A. (2007): Hirsch-index for Countries Based on Essential Science Indicators Data. Scientometrics, 73, No. 1, pp. $91-117$. DOI: 10.1007/s11192-007-1859-9.

CUI, Y. L. (2020): Global Research Landscape of High-level Studies in Geosciences Based on Highly Cited Papers. Current Science India, 118, No. 4, pp. $532-542$.

DOI: $10.18520 / \mathrm{cs} / \mathrm{v} 118 / \mathrm{i} 4 / 532-542$.

DE FILIPPO, D. - PANDIELLA-DOMINIQUE, A. - SANZ-CASADO, E. (2017): Indicators for the Analysis of International Visibility in Spanish Universities. Revista de Education, 376, April - June, pp. 163 - 199. DOI: 10.4438/1988-592X-RE-2017-376-348.

DE FILIPPO, D. - SANZ-CASADO, E. (2018): Bibliometric and Altmetric Analysis of Three Social Science Disciplines. Front. Res. Metr. Anal, December 6. DOI: $10.3389 /$ frma.2018.00034

DI VAIO, G. - WALDENSTRÖM, D. - WEISDORF, J. (2012): Citation Success: Evidence from Economic History Journal Publications. Explorations in Economic History, 49, pp. $92-104$.

FRONTIERS (2019): Increasing the Visibility of Research in the Social Science and Humanities. Available at: <https://www.frontiersin.org/research-topics/7271/increasing-the-visibility-ofresearch-in-the-social-sciences-and-humanities-ssh>.

FU, H. Z. - CHUANG, K. Y. - WANG, M. H. - HO, Y. S. (2011): Characteristics of Research in China Assessed with Essential Science Indicators. Scientometrics, 88, No. 3, pp. $841-862$. DOI: $10.1007 / \mathrm{s} 11192-011-0416-8$.

GALVEZ, C. (2018): Co-word Analysis Applied to Highly Cited Papers in Library and Information Science (2007 - 2017). Transinformacao, 30, No. 3, pp. 277 - 286. DOI: $10.1590 / 2318-08892018000300001$.

GAUTAM, P. (2017): An Overview of the Web of Science Record of Scientific Publications (2004 - 2013) from Nepal: Focus on Disciplinary Diversity and International Collaboration. Scientometrics, 113, No. 3, pp. 1245 - 1267. DOI: 10.1007/s11192-017-2538-0.

GAUTAM, P. (2015): Deciphering the Department-Discipline Relationships within a University through Bibliometric Analysis of Publications Aided with Multivariate Techniques. In: MATSUO, T., HASHIMOTO, K., MINE, T. and HIROKAWA, S. (eds): 4th International Congress on Advanced Applied Informatics (IIAI-AAI). New York: IEEE, pp. 468 - 471. ISBN 978-1-4799-9958-3. DOI: 10.1109/IIAI-AAI.2015.212.

GDI (2018): Gender Diversity Impact - Project Deliverable. D4.3 Survey Analysis and Performance Indicator. [Research Report. Version 1.0 FINAL. 24th March.] Project Coordinaton: MULLER, J. et al. Barcelona: Universitat Oberta de Catalunya.

GHANE, M. R. - KHOSROWJERDI, M. - AZIZKHANI, Z. (2013): The Ranking of Iranian Universities Based on an Improved Technique. Malaysian Journal of Library \& Information Science, 18 , No. 2, pp. $33-45$.

GIBSON, J. - ANDERSON, D. L. - TRESSLER, J. (2017): Citations or Journal Quality: Which is Rewarded More in the Academic Labor Market? Economic Inquiry, 55, No. 4, pp. 1945 - 1965.

HAMERMESH, D. S. - PFANN, G. A. (2012): Reputation and Earnings: The Roles of Quality and Quantity in Academe. Economic Inquiry, 50, No. 1, pp. $1-16$.

HELBIG, K. - HAUSSTEIN, B. - TOEPFER, R. (2015): Supporting Data Citation: Experiences and Best Practices of a DOI Allocation Agency for Social Sciences. Journal of Librarianship and Scholarly Communication, 3, No. 2, eP1220. Available at: <http://dx.doi.org/10.7710/2162-3309.1220>.

HU, X. J. (2007): Relative Superiority Coefficient of Papers: A New Dimension for Institutional Research Performance in Different Fields. Scientometrics, 72, No. 3, pp. 389 - 402, DOI: 10.1007/s11192-006-1733-1.

HU, X. J. - LEYDESDORFF, L. - ROUSSEAU, R. (2020): Exponential Growth in the Number of Items in the WoS. ISSI Newsletter, 16, No. 2, pp. $32-38$. 
HU, X. J. - ROUSSEAU, R. (2009): A Comparative Study of the Difference in Research Performance in Biomedical Fields among Selected Western and Asian Countries. Scientometrics, 81, No. 2, pp. 475 - 491. DOI: 10.1007/s11192-008-2202-9.

HUANG, M. H. - CHANG, H. W. (2005): Research Evaluation of Research-oriented Universities in Taiwan. In: INGWERSEN, P. and LARSEN, B. (eds): ISSI 2005: Proceedings of the 10th International Conference of the International Society for Scientometrics and Informetrics. Vols. 1 and 2. Stockholm: Karolinska University Press AB, pp. $247-250$. ISBN 91-7140-339-6, 2005.

HUANG, M. H. - CHANG, H. W. - CHEN, D. Z. (2006): Research Evaluation of Researchoriented Universities in Taiwan from 1993 to 2003. Scientometrics, 67, No. 3, pp. $419-435$. DOI: 10.1556/Scient.67.2006.3.6.

IOANNIDIS, J. P. A. - KLAVANS, R. - BOYACK, K. W. (2018): The Scientists Who Publish a Paper Every Five Days. Nature, 561, September, pp. 167 - 169. Supplementary Information Link - go.nature.com/2phadg2.

JANSSENS, F. - ZHANG, L. - DE MOOR, B. - GLANZEL, W. (2009): Hybrid Clustering for Validation and Improvement of Subject-classification Schemes. Information Processing \& Management, 45, No. 6, pp. 683 - 702. DOI: 10.1016/j.ipm.2009.06.003.

JEENAH, M. - POURIS, A. (2008): South African Research in the Context of Africa and Globally. South African Journal of Science, 104, No. 9 - 10, pp. 351 - 354.

KHARABAF, S. - ABDOLLAHI, M. (2012): Science Growth in Iran over the Past 35 Years. Journal of Research in Medical Sciences, 17, No. 3, pp. $275-279$.

KREMER, R. K. - MARX, W. (2009): Aspects of the Scientific Cooperation of Estonia and Germany in View of Bibliometry. [Proceedings of the Estonian Academy of Sciences.] Tallinn: Estonian Academy Publishers, 58, No. 4, pp. 255 - 262. DOI: 10.3176/proc.2009.4.07.

LEMKE, S. - MEHRAZAR, M. - MAZARAKIS, A. - PETERS, I. (2019): When You Use Social Media You Are Not Working: Barriers for the Use of Metrics in Social Sciences. Front. Res. Metr. Anal., January. DOI: 10.3389/frma.2018.00039.

LEYDESDORF, L. (2008): Caveats for the Use of Citaton Indicators in Research and Journal Evaluations. Journal of the American Society for Informaton Science and Technology, 59, No. 2, pp. $278-287$.

LIAO, H. C. - TANG, M. - LI, Z. M. - LEV, B. (2019): Bibliometric Analysis for Highly Cited Papers in Operations Research and Management Science from 2008 to 2017 Based on Essential Science Indicators. OMEGA - International Journal of Management Science, 88 , October, pp. 223 - 236. DOI: 10.1016/j.omega.2018.11.005.

LIU, Y. X. - ROUSSEAU, R. (2010): Knowledge Diffusion through Publications and Citations: A Case Study Using ESI - Fields as Unit of Diffusion. Journal of the American Society for Information Science and Technology, 61, No. 2, pp. 340 - 351. DOI: 10.1002/asi.21248.

LU, H. - FENG, Y. (2009): A Measure of Authors' Centrality in Co-authorship Networks Based on the Distribution of Collaborative Relationships. Scientometrics, 81, No. 2, pp. $499-511$.

MA, Q. - LI, Y. D. - ZHANG, Y. (2020): Informetric Analysis of Highly Cited Papers in Environmental Sciences Based on Essential Science Indicators. International Journal of Environmental Research and Public Health, 17, No. 11, pp. 37 - 81. DOI: 10.3390/ijerph17113781.

MARKUSOVA, V. A. - TSYGANKOVA, A. I. - KRYLOVA, T. A. (2009): The Indices of Scientific Productivity and Ratings of Domestic Universities. Scientific and Technical Information Processing, 36, No. 4, pp. 229 - 233. DOI: 10.3103/S0147688209040066.

MIYAIRI, N. - CHANG, H. W. (2012): Bibliometric Characteristics of Highly Cited Papers from Taiwan, 2000 - 2009. Scientometrics, 92, No. 1, pp. $197-205$. DOI: $10.1007 / \mathrm{s} 11192-012-0722-9$.

MOKHNACHEVA, Y. V. - KHARYBINA, T. N. (2011): Research Performance of RAS Institutions and Russian Universities: A Comparative Bibliometric Analysis. Herald of the Russian Academy of Sciences, 81, No. 6, pp. 569 - 574. DOI: 10.1134/S1019331611060104. 
MORAL-MUNOZ, J. A. - SALAZAR, A. - LUCENA-ANTON, D. - GARCIA-SANCHEZ, P. COBO, M. J. (2019): Social Media Attention of the ESI Highly Cited Papers: An Altmetricsbased Overview. In: CATALANO, G., DARAIO, C., GREGORI, M., MOED, H. F. and RUOCCO, G. (eds): Proceedings of the 17th International Conference on Scientometrics and Informetrics (ISSI2019), VOL II, pp. 1734 - 1745. ISBN 978-88-3381-118-5.

NARIN, F. - HAMILTON, K. S. (1996): Bibliometric Performance Measures. Scientometrics, 36, No. 3, pp. $293-310$.

ONYANCHA, O. B. (2020): Research Excellence in the Era of Online Attention: Altmetrics of South Africa's Highly Cited Papers in Selected Research Fields. Publishing Research Quarterly, 36, No. 1, pp. 169 - 185. DOI: 10.1007/s12109-019-09679-z.

PISLYAKOV, V. V. (2011): The Masterpieces of Scientific Creativity: An Analysis of Highly Cited Papers by Russian Scientists. Automatic Documentation and Mathematical Linguistics, 45, No. 6, pp. 293 - 300. DOI: 10.3103/S0005105511060070.

POURIS, A. (2007): The International Performance of the South African Academic Institutions: A Citation Assessment. Higher Education, 54, No. 4, pp. 501 - 509. DOI: 10.1007/s10734-006-9034-4.

PRATHAP, G. (2010): An iCE map Approach to Evaluate Performance and Efficiency of Scientific Production of Countries. Scientometrics, 85, No. 1, pp. $185-191$. DOI: 10.1007/s11192-010-0192-x.

QIN, F. - DU, J. - GAO, J. - LIU, G. Y. - SONG, Y. G. - YANG, A. F. - WANG, H. - DING, Y. - WANG, Q. (2020): Bibliometric Profile of Global Microplastics Research from 2004 to 2019. International Journal of Environmental Research and Public Health, 17, No. 16. DOI: 10.3390/ijerph17165639.

SANDSTRÖM, U. - BESSELAAR, P. van den (2016): Quantity and/or Quality? The Importance of Publishing Many Papers. PLoS ONE, 11, No. 11, pp. e0166149. DOI: 10.1371/journal.pone.0166149.

SANZ-MENÉNDEZ, L. - BORDONS, M. - ZULUETA, M. A. (2001): Interdisciplinarity as a Multidimensional Concept: Its Measure in Three Different Research Areas. Research Evaluation, 10, No. 1, pp. 47 - 58. Available at: 〈https://doi.org/10.3152/147154401781777123>.

SCIENCE (2018): Migration Brings Citations Boost. Science, 361, No. 6409, pp. 1296.

SHUANG, Y. Q. - GAO, W. H. - PANG, M. H. (2016): A Comparative Study on the Highly Cited Papers of the Top Eight Engineering Universities. Collnet Journal of Scientometrics and Information Management, 10, No. 2, pp. 311 - 320. DOI: 10.1080/09737766.2016.1229908.

SIMONS, N. (2012): Implementing DOIs for Research Data. D-Lib Magazine, 18, No. 5/6. Available at: 〈http://dx.doi.org/10.1045/may2012-simons>.

SMALL, H. (2004): Why Authors Think Their Papers Are Highly Cited. Scientometrics, 60, No. 3, pp. 305 - 316. DOI: 10.1023/B:SCIE.0000034376.55800.18.

SUN, J. - YUAN, B. Z. (2021): Trend and Research Status of Agronomy Based on the Essential Science Indicators during 2009 - 2019. Agronomy Journal, 113, No. 2, pp. 2184 - 2194. DOI: $10.1002 / \mathrm{agj} 2.20628$.

SUN, J. - YUAN, B. Z. (2020a): Mapping of Top Papers in the Subject Category of Water Resources Based on the Essential Science Indicators. Annals of Library and Information Studies, 67, No. 2, pp. $90-102$.

SUN, J. - YUAN, B. Z. (2020b): Mapping of the World Rice Research: A Bibliometric Analysis of Top Papers during 2008 - 2018. Annals of Library and Information Studies, 67, No. 1, pp. $56-66$.

SUN, J. - YUAN, B. Z. (2020c): Bibliometric Mapping of Top Papers in Library and Information Science Based on the Essential Science Indicators Database. Malaysian Journal of Library \& Information Science, 25, No. 2, pp. 61 - 76. DOI: 10.22452/mjlis.vol25no2.4.

SZOMSZOR, M. - PENDLEBURY, D. A. - ADAMS, J. (2020): How Much Is Too Much? The Difference between Research Influence and Self-citation Excess. Scientometrics, 123, No. 2, pp. 1119 - 1147. DOI: 10.1007/s11192-020-03417-5. 
VIIU, G. A. - PAUNESCU, M. (2021): The Citation Impact of Articles from which Authors Gained Monetary Rewards Based on Journal Metrics. Scientometrics, 126, No. 6, pp. $4941-4974$. DOI: 10.1007/s11192-021-03944-9.

WAN, S. S. - ZHANG, N. - WANG, P. L. - ZHANG, P. - WU, Q. (2017): A Brief Analysis of Top Scientists in the Field of Economics and Business Based on the Essential Science Indicators Database. In: ATANASSOVA, I., BERTIN, M. and MAYR, P. (eds): Proceedings of the 16th International Conference on Scientometrics \& Informetrics (ISSI 2017). Leuven: Katholieke Univ. Leuven, 2175 - 1935, pp. 896 - 901.

WANG, F. H. - FAN, Y. - ZENG, A. - DI, Z. R. (2019): Can We Predict ESI Highly Cited Publications? Scientometrics, 118, No. 1, pp. 109 - 125. DOI: 10.1007/s11192-018-2965-6.

WANG, M. H. - FU, H. Z. - HO, Y. S. (2011): Comparison of Universities' Scientific Performance Using Bibliometric Indicators. Malaysian Journal of Library \& Information Science, 16, No. 2, pp. $1-19$.

YANG, D. H. - WANG, Y. - YU, T. - LIU, X. Y. (2020): Macro-level Collaboration Network Analysis and Visualization with Essential Science Indicators: A Case of Social Sciences. Malaysian Journal of Library \& Information Science, 25, No. 1, pp. 121 - 138. DOI: $10.22452 / \mathrm{mjlis}$. vol25no1.7.

YU, D. J. - XU, Z. S. (2019): Characteristics of Fuzzy Researches: A Bibliometric Analysis Based on Essential Science Indicators. Journal of Multiple-valued Logic and Soft Computing, 32, No. $1-2$, pp. $1-25$.

YUAN, B. Z. - SUN, J. (2020): Bibliometric Analysis of Research on the Maize Based on Top Papers during 2009 - 2019. Collnet Journal of Scientometrics and Information Management, 14, No. 1, pp. 75 - 92. DOI: 10.1080/09737766.2020.1787110.

YUAN, B. Z. - SUN, J. (2019): Bibliometric and Mapping of Top Papers in the Subject Category of Green and Sustainable Science and Technology Based on ESI. Collnet Journal of Scientometrics and Information Management, 13, No. 2, pp. 269 - 289. DOI: 10.1080/09737766.2020.1716643.

ZAVADSKAS, E. K. - KIRVAITIS, R. - DAGIENE, E. (2011): Scientific Publications Released in the Baltic States. Scientometrics, 88, No. 1, pp. 179 - 190. DOI: 10.1007/s11192-011-0394-x.

ZHAI, T. - DI, L. Z. (2019): Information Mining and Visualization of Highly Cited Papers on Type-2 Diabetes Mellitus from ESI Current Science India, 116, No. 12, pp. 1965 - 1974. DOI: $10.18520 / \mathrm{cs} / \mathrm{v} 116 / \mathrm{i} 12 / 1965-1974$.

ZHANG, L. - JANSSENS, F. - LIANG, L. M. - GLANZEL, W. (2009): Hybrid Clustering Analysis for Mapping Large Scientific Domains. In: LARSEN, B. and LETA, J. (eds): Proceedings of ISSI 2009 - 12th International Conference of the International Society for Scientometrics and Informetrics, 1 , pp. $178-188$.

ZHANG, N. - WAN, S. S.- WANG, P. L. - ZHANG, P. - WU, Q. (2018): A Bibliometric Analysis of Highly Cited Papers in the Field of Economics and Business Based on the Essential Science Indicators Database. Scientometrics, 116, No. 2, pp. 1039 - 1053. DOI: $10.1007 / \mathrm{s} 11192-018-2786-7$.

ZHOU, Y. P. (2021): Self-citation and Citation of Top Journal Publishers and Their Interpretation in the Journal-discipline Context. Scientometrics, 126, No. 7, pp. $6013-6040$. DOI: 10.1007/s11192-021-03995-y. 


\section{A p pendix}

Table 2

Descriptive Statistics for WoS, CIT, CITP and TOPP Data

\begin{tabular}{|l|l|l|l|l|}
\hline & WoS & CIT & CITP & TOPP \\
\hline Mean & 289.1363 & $6,570.833$ & 62.69898 & 9.465534 \\
Median & 105.0000 & $3,350.000$ & 29.01000 & 4.000000 \\
Maximum & $52,278.00$ & $663,490.0$ & $10,586.00$ & 798.0000 \\
Minimum & 1.000000 & 475.0000 & 0.320000 & 0.000000 \\
Std. Dev. & 879.5909 & $12,321.80$ & 189.6157 & 17.09562 \\
Skewness & 21.65853 & 16.90734 & 16.80327 & 11.00968 \\
Kurtosis & 822.7398 & 574.5968 & 499.1147 & 292.4208 \\
Sum & $25,632,803$ & $5.83 \mathrm{E}+08$ & $5,558,453.0$ & $839,148.0$ \\
Sum Sq. dev. & $6.86 \mathrm{E}+10$ & $1.35 \mathrm{E}+13$ & $3.19 \mathrm{E}+09$ & $25,909,460$ \\
Observations & 88,653 & 88,653 & 88,653 & 88,653 \\
\hline
\end{tabular}

Source: Own computations.

Table 3

Overview of Various Research Assessment Measures and Their Acronyms

\begin{tabular}{|l|l|}
\hline \multicolumn{1}{|c|}{ Acronym } & \multicolumn{1}{c|}{ Full name } \\
\hline 2 YIF & Classic 2-year impact factor \\
2 YIF* & 2YIF without journal self-citations \\
5 YIF & 5-year impact factor \\
0YIF & 0-year impact factor \\
IFI & Impact Factor Inflation \\
STAR & Self-citation Threshold Approval Rating \\
ES & Eigenfactor score \\
ArtI & Article Influence \\
C3PO & Citation Performance Per Paper Online \\
HI & h-index \\
PI-BETA & Papers Ignored -By Even The Authors \\
Z & Z-influence \\
\hline
\end{tabular}

Source: Own compilation.

Table 4

Model A - Regression Analysis Cites vs. WoS $(\mathrm{N}=88,646)$

\begin{tabular}{|c|c|c|c|c|c|c|}
\hline \multicolumn{7}{|c|}{ Regression Analysis - Linear model: MOD-A $\mathrm{A}_{\mathrm{Cites}}=2818,68+12,9777 * \mathrm{MOD}-\mathrm{A}_{\mathrm{WoS}}$} \\
\hline \multicolumn{2}{|c|}{ Dependent variable: Cites } & \multicolumn{5}{|c|}{ Independent variable: WoS } \\
\hline Parameter & Estimate & \multicolumn{2}{|c|}{ Standard Error } & \multicolumn{2}{|c|}{ T Statistic } & P-Value \\
\hline Intercept & 2818,68 & \multicolumn{2}{|c|}{16,4019} & \multicolumn{2}{|c|}{171,851} & 0,0000 \\
\hline \multirow[t]{2}{*}{ Slope } & 12,9777 & \multicolumn{2}{|c|}{0,0177142} & 732 & \multicolumn{2}{|c|}{0,0000} \\
\hline & \multicolumn{6}{|c|}{ Analysis of Variance } \\
\hline Source & Sum of Squares & Df & Mear & & F-Ratio & P-Value \\
\hline Model & $1,15517 \mathrm{E} 13$ & 1 & 1,15 & & 536730,02 & 0,0000 \\
\hline Residual & $1,90785 \mathrm{E} 12$ & 88645 & 2,15 & & & \\
\hline Total (Corr.) & $1,34595 \mathrm{E} 13$ & 88646 & & & & \\
\hline \multicolumn{7}{|c|}{ Correlation Coefficient $=0,926419$} \\
\hline \multicolumn{7}{|c|}{ R-squared $=85,8253 \%$} \\
\hline Standard Erro & t. $=4639,22$ & & & & & \\
\hline
\end{tabular}

Source: Own computation. 
Table 5

Model B - Regression Analysis Cites vs. Top Publications ( $\mathrm{N}=88,646)$

\begin{tabular}{|c|c|c|c|c|c|c|c|}
\hline \multicolumn{8}{|c|}{ Regression Analysis - Linear model: MOD-C $\mathrm{C}_{\text {Cites }}=306,776+661,784 * \mathrm{MOD}-\mathrm{C}_{\text {Top publications }}$} \\
\hline \multicolumn{2}{|c|}{ Dependent variable: Cites } & \multicolumn{6}{|c|}{ Independent variable: Top publications } \\
\hline Parameter & Estimate & \multicolumn{2}{|c|}{ Standard Error } & \multicolumn{2}{|c|}{ T Statistic } & \multicolumn{2}{|l|}{ P-Value } \\
\hline Intercept & 306,776 & \multicolumn{2}{|c|}{18,7414} & \multicolumn{2}{|c|}{16,3689} & \multicolumn{2}{|l|}{0,0000} \\
\hline \multirow[t]{2}{*}{ Slope } & 661,784 & 0,95904 & & 690 & & 0,0000 & \\
\hline & \multicolumn{7}{|c|}{ Analysis of Variance } \\
\hline Source & Sum of Squares & Df & Mea & & F-Ratio & & P-Value \\
\hline Model & $1,13471 \mathrm{E} 13$ & 1 & 1,13 & & 476161,07 & & 0,0000 \\
\hline Residual & $2,11244 \mathrm{E} 12$ & 88645 & 2,38 & & & & \\
\hline Total (Corr.) & $1,34595 \mathrm{E} 13$ & 88646 & & & & & \\
\hline \multicolumn{8}{|c|}{ Correlation Coefficient $=0,918179$} \\
\hline \multicolumn{8}{|c|}{$\mathrm{R}$-squared $=84,3052 \%$} \\
\hline Standard Erro & $t .=4881,63$ & & & & & & \\
\hline
\end{tabular}

Source: Own computation.

Table 6

The Specific Rankings of Research Item's Citation (economic literature)

\begin{tabular}{|llccc|}
\hline Rank & Item & Citations & Number of authors (a) & Date of publication (b, c) \\
\hline 1. & Researcher(s) A & 6231 & 2 & 1991 \\
\hline 2. & Researcher(s) B & 5155 & 2 & 1987 \\
\hline 3. & Researcher(s) C & 5071 & 1 & 1979 \\
\hline 4. & Researcher(s) D & 4930 & 2 & 1979 \\
\hline 5. & Researcher(s) E & 4897 & 2 & 1976 \\
\hline 6. & Researcher(s) F & 4856 & 2 & 1995 \\
\hline 7. & Researcher(s) G & 4768 & 1 & 1988 \\
\hline 8. & Researcher(s) H & 4475 & $1 / 1$ & $1988 / 1986$ \\
\hline 9. & Researcher(s) I & 4354 & 1 & 1986 \\
\hline 10. & Researcher(s) J & 4282 & 1 & 1980 \\
\hline$\ldots$ & & & 1 & 1974 \\
\hline 50. & Researcher(s) X & 2106 & & many cases (e) \\
\hline$\ldots$ & & & 1 & many cases (e) \\
\hline 100. & Researcher(s) Y & 1485 & many cases (d) & \\
\hline$\ldots$ & & & many cases (d) & \\
\hline 1002. & Researcher(s) W & 437 & & \\
\hline$\ldots$ & & & & \\
\hline 2799. & Researcher(s) Z & 239 & & \\
\hline
\end{tabular}

General note: These citation figures are experimental and based on the citation analysis provided by the CitEc project, which uses data from items listed in RePEc.

Specific notes: (a) Example 1/1 means two separate authors with the same number of citations;

(b) Date of first publication - no reprint dates included;

(c) $1988 / 1986$ = two separate authors date of publication;

(d) There are many cases of authors/publications with the same number of citations;

(e) Referring to note "d" there are various dates of publication.

Source: Own compilation and specification based on CitEc/RePEc data. 
T a ble 7

Factors Contributing to Success of Hyper-prolific Researchers

\begin{tabular}{|c|c|}
\hline Factor & Explanation/example \\
\hline ROADMAP & having a roadmap to achieve the goal \\
\hline TEAM and COOPERATION & $\begin{array}{l}\text { team leader, leadership of a research team, management of projects, } \\
\text { have a close engagement to the colleagues in a team, collaboration } \\
\text { of the members, the support and guidance of my colleague, highly } \\
\text { collaborative lab, a professional, expert; the mentoring of fellows, } \\
\text { appetite for scientific communication; working in the highly } \\
\text { productive environment and working with the right people }\end{array}$ \\
\hline TEACHING and PHD SUPERVISING & $\begin{array}{l}\text { delivering and teaching high quality, supervise, directly or } \\
\text { indirectly many PhD students, achievement is mainly due to } \\
\text { association with many young and productive postgraduate students; } \\
\text { enjoyed close and productive collaboration both with own many } \\
\text { PhD students as well as with a comparable number of valued } \\
\text { international academic colleagues }\end{array}$ \\
\hline SPECIALIZATION & $\begin{array}{l}\text { work on focused research fields to be expert on that field (not } \\
\text { research on everything), wide research team, and be part of a large } \\
\text { consortium of authors; relevant research and type of research } \\
\text { (e.g., in case of clinical research if you have a question, you will } \\
\text { get an answer (positive or negative) in a predefined time frame }\end{array}$ \\
\hline $\begin{array}{l}\text { INTERNATIONAL PROJECT } \\
\text { PARTICIPATION }\end{array}$ & $\begin{array}{l}\text { participation in many international projects, involvement in major } \\
\text { research projects; collaboration with colleagues in many countries; } \\
\text { involved in international consortia (e.g., focused on genomic } \\
\text { research, major international clinical trials) and EU sponsored } \\
\text { projects }\end{array}$ \\
\hline MULTIPLE-USE PRODUCTS & $\begin{array}{l}\text { developing algorithms and releasing open software; large number } \\
\text { of collaborators in particular research areas who use our invaluable } \\
\text { cohort resources (questionnaire; physical exam and specific } \\
\text { samples); to be in charge of different databases issued from } \\
\text { cohorts, registries, international cross-sectional studies provided } \\
\text { that the access to the database is transparent and open (for free) } \\
\text { to the entire research community; collecting the data (longitudinal } \\
\text { follow-up of clinical, biological, etc.) }\end{array}$ \\
\hline $\begin{array}{l}\text { REPUTATION and PERSONAL } \\
\text { CHARACTERISTICS }\end{array}$ & $\begin{array}{l}\text { relatively late career that enhances productivity/reputation; won } \\
\text { several awards; committed to high quality research the results } \\
\text { of which, positive or negative, should become available to the } \\
\text { international scientific community through publications; started } \\
\text { a new research group, work on a daily basis with post-docs and } \\
\text { other staff; never give up on small things and seemingly worthless } \\
\text { phenomena and never ignore them hopping that there are bigger } \\
\text { works to do; every research can be someday valuable; occasional } \\
\text { work for guidelines or invited editorials etc.; Work at the office, } \\
\text { or at home from } 5 \text { am to } 11 \mathrm{pm} \text {, sometimes early experiences have } \\
\text { a lasting impact }\end{array}$ \\
\hline GOOD SKILLS & $\begin{array}{l}\text { good writing skills, international papers, contributions to the } \\
\text { published papers; interpreting the results, writing papers and } \\
\text { teaching PhD students to submit papers to journals indexed in } \\
\text { SCOPUS }\end{array}$ \\
\hline $\begin{array}{l}\text { INFRASTRUCTURE, TECHNOLOGY, } \\
\text { and CULTURE }\end{array}$ & $\begin{array}{l}\text { the result of a focused, efficient and science driven culture; } \\
\text { the strategy, culture and infrastructure focused to promote research; } \\
\text { announced a change from a "traditional" (subscription) to an } \\
\text { open-access publication model }\end{array}$ \\
\hline
\end{tabular}

Source: Own elaboration, based on database related to Ioannidis, Klavans and Boyack (2018). 